\title{
BMJ Open Time series analysis of the incidence of acute upper respiratory tract infections, COVID-19 and the use of antibiotics in Finland during the COVID-19 epidemic: a cohort study of 833444 patients
}

\author{
Oskar Niemenoja (D) , ${ }^{1}$ Ara Taalas, ${ }^{1,2}$ Simo Taimela (D) , ${ }^{1,3}$ Petri Bono, ${ }^{1,4}$ \\ Pentti Huovinen, ${ }^{5}$ Sari Riihijärvi (i) ${ }^{1}$
}

To cite: Niemenoja 0, Taalas A, Taimela S, et al. Time series analysis of the incidence of acute upper respiratory tract infections, COVID-19 and the use of antibiotics in Finland during the COVID-19 epidemic: a cohort study of 833444 patients. BMJ Open 2022;12:e046490. doi:10.1136/ bmjopen-2020-046490

- Prepublication history and additional supplemental material for this paper are available online. To view these files, please visit the journal online (http://dx.doi.org/10.1136/ bmjopen-2020-046490).

Received 31 October 2020 Accepted 27 December 2021

Check for updates

(C) Author(s) (or their employer(s)) 2022. Re-use permitted under CC BY-NC. No commercial re-use. See rights and permissions. Published by BMJ.

For numbered affiliations see end of article.

Correspondence to

Dr Sari Riihijärvi;

sari.riihijarvi@icloud.com

\section{ABSTRACT}

Objective To evaluate the trajectories of acute upper respiratory tract infections (URTIS), COVID-19, and the use of antibiotics in Finland during the COVID-19 epidemic. Design Population-based cohort study.

Setting Electronic medical records from a nationwide healthcare chain in Finland.

Participants 833444 patients from a cohort of 1970013

Finns who had used medical services between 2017 and 2020.

Main outcome measures Number of weekly patients of acute URTIs, COVID-19, and the prescribed number of antibiotics in Finland between 6 January 2020 and 21 June 2020. We estimated the respective expected numbers from 1 March 2020 onward using autoregressive integrated moving average model from 1 January 2017 to 1 March 2020. We assessed the public interest in COVID-19 by collecting Google search trend frequencies. Results There was a rapid increase in COVID-related internet searches between weeks 10 and 12. At the same time, there was a $106 \%$ increase in diagnoses of acute URTIs, from 410 per 100000 inhabitants to 845 per 100 000. The first COVID-19 cases were diagnosed on week 11. Prescriptions for URTI-related antibiotics declined by $71 \%$ (403 per 100000 to 117 per 100 000) between weeks 11 and 15 while no relevant change took place in prescriptions of antibiotics for urinary tract infections. Conclusions At the beginning of the epidemic, many people contacted healthcare professionals with relatively mild symptoms, as indicated by the reduced rate of URTIantibiotics prescriptions. Our findings indicate that health service providers should be prepared for rapid variations in service demand. Securing access of true COVID-19 patients to proper diagnostics, care and isolation measures may help in preventing the spread of the disease.

\section{INTRODUCTION}

The ongoing global pandemic due to the spread of SARS-CoV-2 has plunged multiple societies into crisis, both in terms of the sustainability of the healthcare sector and the financial system. ${ }^{1}$ Although the COVID-19
Strengths and limitations of this study

- The population-based cohort study had access to prospectively collected and homogeneous registry data, comprising a large proportion (15\%) of the Finnish population.

- Users of private health services may not be representative of the overall Finnish population, which limits generalisability. Study conducted in one country limits generalisability.

- The study had access to a large set of data from the previous years, using which we were able to estimate the expected numbers for the selected outcomes with reasonable accuracy using the autoregressive integrated moving average model.

- The study had access to a control group in the incidence of acute urinary tract infection prevalence over the study period.

- Simultaneity of phenomena does not imply cause and effect.

pathology and epidemiology have been widely studied, only little is known about the utilisation of healthcare services for respiratory systems during the pandemic.

Like other respiratory viruses, the most common symptoms of COVID-19 infection include fever and cough. ${ }^{2}$ The distinction between different viral upper respiratory tract infections (URTIs) is loosely based on the location of symptoms, with the common cold affecting primarily the nose, throat and lungs. Symptoms are often mild, selfdiagnosis is frequent, and medical attention rarely needed. ${ }^{34}$ Isolation of the viral agent involved is rarely performed, and it is generally not possible to identify the virus type from the symptoms. This creates a challenge for the attending physicians in the diagnostics of COVID-19 in individual patients and 


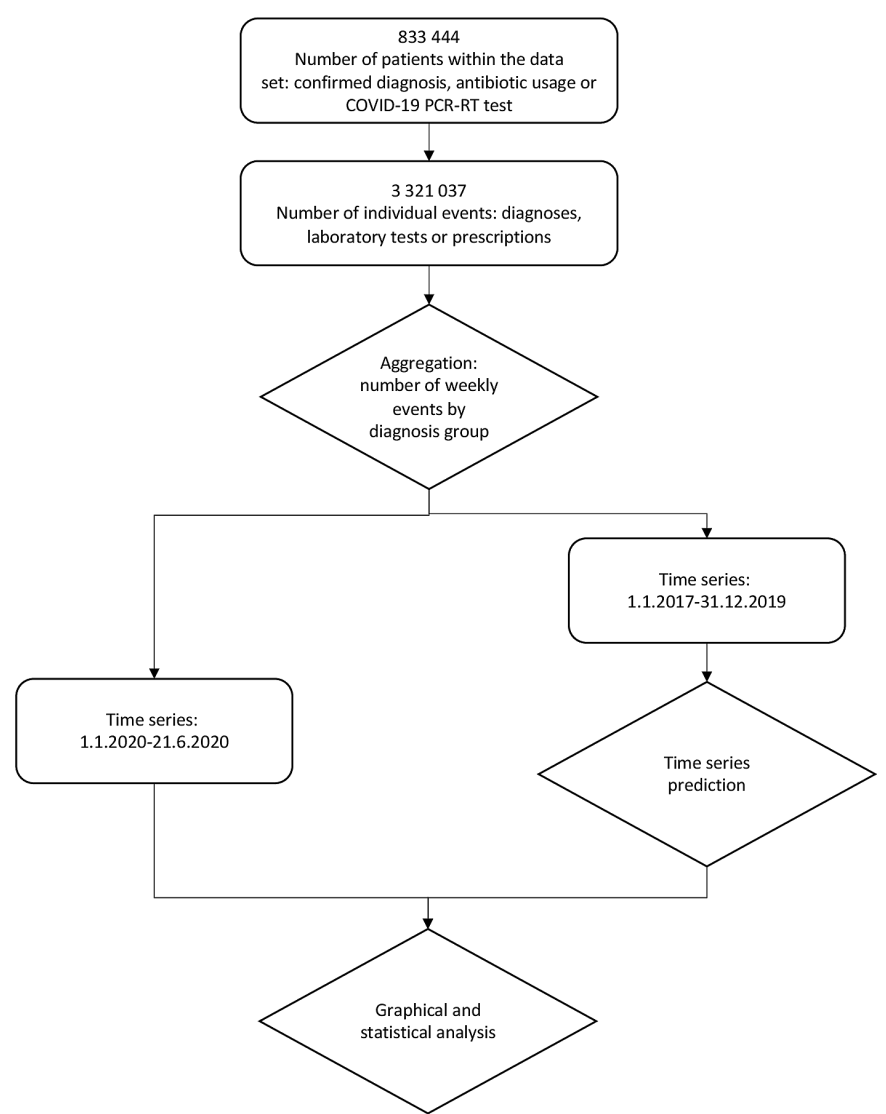

Figure 1 Study design and relevant steps. Data sets are depicted with a rounded box and processing and analytics with a diamond. From the overall population, we included all patients with the predefined conditions, which were aggregated to the number of events per week. The years 2017-2019 were used to model typical behaviour of patients during weeks 2-25, and these predictions were combined with observed data from 2020 to study the effect of COVID-19 on the healthcare system. PCR-RT, COVID-19 PCR test real time.

the healthcare system at large in arranging the resources for the diagnostics and care of the patients.

We present findings of a time series analysis of the incidence of URTIs, confirmed COVID-19 infections, prescriptions for antibiotics against URTIs and concomitant public interest in COVID-19 in Finland during the COVID-19 epidemic. We also calculated expected incidences for the diagnoses and prescriptions based on data from 3 years preceding the COVID-19 epidemic.

\section{METHODS}

\section{Study design}

The study design is a retrospective analysis of prospectively collected register data. The data were collected from electronic patient registers of one nationwide health service provider (Terveystalo) in Finland. Figure 1 shows the study process followed. Data privacy was strictly followed.

\section{Setting}

In Finland, the first case of COVID-19 was diagnosed in February 2020. From 18 March 2020 onwards, a series of nationwide control measures, based on a series of acts by the Finnish parliament, were applied to restrict the spread of the COVID-19 epidemic. From 19 April 2020 onwards, the restrictions were gradually lifted. Altogether 7236 confirmed cases and 328 COVID-19-related deaths had been confirmed by 1 July $2020 .^{5}$ In July-August 2020 , the rate of new COVID-19 infections remained at low level.

Healthcare in Finland is mainly composed of publicly funded healthcare, provided either by public or private providers. The publicly funded healthcare constituted $75.8 \%$ of all healthcare costs in 2018, while the private healthcare services accounted for the rest. ${ }^{6}$ Both the public and private health services are available across Finland.

Terveystalo is the largest private healthcare service company in Finland offering primary and secondary healthcare services for corporate and private customers as well as the public sector. The nationwide network includes approximately 300 health service units across Finland and 13000 medical doctors. In 2019, Terveystalo had approximately 1.2 million individual customers with approximately 3.7 million visits to a physician, amounting to approximately $15 \%$ of all physician visits in Finland. Patients can attend the services via an in-person appointment, or a digital appointment, and no distinction was made between these service channels in the this study. All diagnoses and prescriptions are recorded into a centralised electronic health record system. Alongside the outpatient clinic network, Terveystalo provides laboratory services in 123 units around Finland.

A more detailed description of the Finnish healthcare setting, and the role of Terveystalo as a service provider is presented in online supplemental appendix A.

\section{Data sources and collection}

Data were collected from the patient database on 1 July 2020. The data set was pseudonymised, and no individual patients were identifiable from the data. All eligible patients were included from all regions of Finland. Overall, the data set contained diagnoses on $1.970 \mathrm{M}$ individuals.

We included all patients $(\mathrm{N}=833444)$ who had either had a COVID-19, an URTI-related diagnosis (table 1), or who had been prescribed certain antibiotics for the time series analysis between the dates 1 January 2017 and 21 June $2020 .{ }^{8}$ We grouped the antibiotics based on their primary use case. Use of antimicrobial agents in outpatients is recommended according to the Current Care Guidelines. These guidelines are widely used in Finland for choice of antibiotics for most common outpatient infectious diseases. ${ }^{9} 10$ The classification on antimicrobials were done following the WHO ATC classification system. ${ }^{11}$ The rate of prescriptions of antibiotics are presented in three categories: respiratory system related 
Table 1 The different diagnosis groups and their reasons for inclusion in the study.

\begin{tabular}{lll}
\hline ICD- code & Diagnosis & Reason for inclusion \\
\hline J06.9 & Acute upper respiratory tract infection, unspecified (URTI) & Similar symptoms with COVID-19 \\
J10 & Influenza, seasonal influenza virus identified & Similar symptoms with COVID-19 \\
N30 & Acute urinary tract infection (UTI) & Reference diagnosis \\
\hline
\end{tabular}

URTI and influenza were chosen because of their similarity with COVID-19 symptoms, where many patients sharing the symptoms were likely to seek medical care. UTI was chosen as a reference group, as the number of patients was estimated to be unaffected by the COVID-19 pandemic.

ICD, International Classification of Diseases.

(URTI), urinary tract related and the rest (table 2). From these data sets, we calculated the weekly number of events by group, which were used for time series analysis.

To assess the public interest in COVID-19, we collected temporal search term frequencies using the Google Trends tool. ${ }^{12}$ We used the keywords 'koronavirus' ('Corona virus'), 'korona' ('Corona') and 'COVID-19' in the six most commonly spoken languages in Finland (Finnish, Swedish, English, Russian, Arabic and Estonian) and limited the analysis for searches made within Finland in year 2020. The resulting measure is a computational measure ranging from 0 to 100 denoting the relative interest in the search terms by day, which we aggregated to a weekly level. The value is linear and relative, with 100 denoting the most interest on the phenomenon during the time series and the value 0 no interest at all.

\section{Statistical methods}

Descriptive statistics were calculated for the study population. Continuous variables were expressed as medians and ranges (10th and 90th percentiles) and categorical variables were summarised as numbers and percentages.

To assess the incidence per 100000 , we calculated the number of patients within the Terveystalo health services. We included all patients who had had an appointment, laboratory test, imaging event or surgery, as well as individuals within the occupational health services during the last 2 years. To calculate the population prevalence, the observed incidence number was adjusted to this number to calculate the incidence per 100000 inhabitants.

We used the autoregressive integrated moving average (ARIMA) model to estimate the expected number of diagnoses during the study period as they would have been without the COVID-19 pandemic. $^{13} 14$ ARIMA deconstructs a time series into lagged values (AR) and linear combinations of past values (MA), after first differentiating the time series one or more times to ensure stationarity (I). The model was fitted using weekly data for all diagnosis groups separately between 1 January 2017 and 1 March 2020, and expected values were predicted for weeks $10-25$ of 2020 . To account for seasonality and yearly variation in the data, four harmonic terms were introduced to the model. The harmonic terms were fitted and applied to all of the models' groups except for N30, which exhibited no seasonality. Quality of the fit was assessed using the Box-Ljung test on the residuals $(\mathrm{p}<0.05) .{ }^{15}$
The calculations were performed using the R statistical language (V.3.6.0) ${ }^{16}$ For the predictions, $95 \%$ CI refers to the 2.5th and 97.5th percentiles of the presented distributions. Parts of the data used have been made available for the public online. ${ }^{17}$

\section{Patient and public involvement}

Patient or the public were not involved in the design, conduct, reporting or dissemination of our research. Parts of the data has been made available to the public.

\section{MAIN RESULTS}

The number of individuals who had had an appointment, laboratory test, imaging event or surgery at Terveystalo, or who were within the occupational health services during the last 2 years by Terveystalo totalled 1970013 people, that is, $35 \%$ of the population of Finland. Of this population, 833444 patients had some of the selected observed diagnoses (table 1) during the observation period. Overall, 3314425 of such events were recorded between 5 different selected conditions. The clinical characteristics of the prospective cohorts of the subjects are listed in table 3. Overall, in Terveystalo, there were 540 PCRpositive COVID-19 cases which comprises $8.0 \%$ of cases in Finland during the observation period.

Figure 2 shows the weekly time series of public interest in COVID-19, the selected diagnoses and prescriptions of antibiotics during year 2020. On week 11 of 2020, the first confirmed COVID-19 cases were reported. Concomitantly, internet searches related to COVID-19 increased sharply. This was accompanied by a 106\% (410 per 100000 to 845 per 100000 ) increase in the incidence of URTIs between weeks 10 and 12. During the same period, the overall number of prescriptions for antibiotics declined by $55 \%$ (657 per 100000 to 299 per 100000 ) between weeks 10 and 15. Seasonal influenza diagnoses (J10) decreased by $79 \%$ (5.5 per 100000 to 1.1 per 100000 ) between weeks 10 and 13 . The values are below the $95 \%$ CIs of the ARIMA prediction during weeks 12 and 13, with near-zero values thereafter. Based on ARIMA-model, the seasonal influenza (J10) period is predicted to end by week 24 but may end as early as at week 14 . During the observation period, the influenza season ended earlier than expected. Based on the ARIMA-model and the observation period, once the observed number of influenza is close to zero, 


\begin{tabular}{lll}
\hline Table 2 & The antibiotics and their groups. & \\
\hline ATC code & Antibiotic name & Antibiotic group \\
\hline J01CA04 & Amoxicillin & $\begin{array}{l}\text { Respiratory tract } \\
\text { J01CR02 }\end{array}$ \\
& $\begin{array}{l}\text { Amoxicillin and beta-lactamase } \\
\text { inhibitor }\end{array}$ & \\
J01CE02 & Phenoxymethylpenicillin & \\
J01AA02 & Doxycycline & \\
J01FA10 & Azithromycin & \\
J01FA09 & Clarithromycin & \\
J01FA06 & Roxithromycin & \\
J01FA15 & Telithromycin & \\
J01FA01 & Erythromycin & Urinary tract \\
J01EA01 & Trimethoprim & infections \\
J01XE01 & Nitrofurantoin & \\
J01CA08 & Pivmecillinam & Other
\end{tabular}

\begin{tabular}{|c|c|c|}
\hline J01DB01 & Cefalexin & Other \\
\hline J01EE01 & $\begin{array}{l}\text { Sulfamethoxazole and } \\
\text { trimethoprim }\end{array}$ & \\
\hline J01AA07 & Tetracycline & \\
\hline J01MA02 & Ciprofloxacin & \\
\hline J01FF01 & Clindamycin & \\
\hline J01AA04 & Lymecycline & \\
\hline J01DC02 & Cefuroxime & \\
\hline J01EE02 & Sulfadiazine and trimethoprim & \\
\hline J01MA12 & Levofloxacin & \\
\hline J01MA14 & Moxifloxacin & \\
\hline J01XC01 & Fusidic acid & \\
\hline $\mathrm{J} 01 \mathrm{X} \times 05$ & Methenamine & \\
\hline J01MA01 & Cfloxacin & \\
\hline J01CF05 & Flucloxacillin & \\
\hline J01DC04 & Cefaclor & \\
\hline J01CE10 & $\begin{array}{l}\text { Benzathine } \\
\text { phenoxymethylpenicillin }\end{array}$ & \\
\hline J01DD04 & Ceftriaxone & \\
\hline J01CE08 & Benzathine benzylpenicillin & \\
\hline J01CE01 & Benzylpenicillin & \\
\hline J01CE09 & Procaine benzylpenicillin & \\
\hline $\mathrm{J} 01 \mathrm{X} \times 01$ & Osfomycin & \\
\hline J01DE01 & Cefepime & \\
\hline $\mathrm{J} 01 \mathrm{X} \times 08$ & Linezolid & \\
\hline J01MA06 & Norfloxacin & \\
\hline J01DH02 & Meropenem & \\
\hline J01DD02 & Ceftazidime & \\
\hline J01GB01 & Tobramycin & \\
\hline J01CA01 & Ampicillin & \\
\hline
\end{tabular}

All prescriptions for antibacterial agents for systemic use (ATC code J01) were considered, and the antibiotics were grouped to denote if they are mainly used in treatment of respiratory tract infections, urinary tract infections, or other infections. The study focused on the change in usage of respiratory tract infection related antibiotics compared with other antibiotics, while UTI-related antibiotics acted as a reference group.

ATC, Anatomical Therapeutic Chemical Classification System. no re-emergence of influenza diagnoses is noted. The incidence of COVID-19 via confirmed laboratory tests peaked on week 13 and again on week 20, after which the number of positive cases declined. After week 15, the number of acute non-specific URTIs fell below the levels of those before the COVID-19 pandemic, with a $72 \%$ decrease in diagnoses on week 19 compared with week 10 (410 per 100000 to 115 per 100000 ). This early increase and later decrease in the number of diagnoses both fall outside the $95 \%$ CIs of the estimated expected numbers for the time period based on the previous years. Also, the decline in the prescriptions for antibiotics exceeds the 95\% confidence limit estimated by ARIMA. As a comparison, no relevant change over time can be observed in urinary tract infections for the same period (figure 2).

The largest relative decrease in the prescriptions of antibiotics took place in those typically used for URTIs as shown in figure 3. Prescriptions of antibiotics for URTI reduced by $71 \%$ from week 11 to week 15 of 2020 , while prescriptions of antibiotics that are typically used for urinary tract infections decreased by $3 \%$ during the same period. Prescriptions of other antibiotics decreased by $38 \%$. Overall, the prescription of antibiotics seems to have been decreasing over the years, although some seasonality is seen in the prescriptions of URTI-related antibiotics also in years 2017 to 2019. However, the total change in antibiotics prescriptions in 2020 is still outside the $95 \%$ CI when accounted for the seasonality, as shown in the figure 2.

Yearly results for the selected diagnoses and prescriptions of antibiotics for the time period during the years 2017-2020 are shown in online supplemental appendix B. Typically for years 2017-2019 the prescription of antibiotics follow the number of URTI-related diagnoses. From year 2020 this pattern changes, with URTI-related diagnoses and antibiotics usage changing independently, as can be seen in figures 2 and 3 .

\section{DISCUSSION \\ Principal findings}

The outburst of the COVID-19 pandemic in Finland was accompanied by broad news and social media coverage, and induced a major public interest in the epidemic, as illustrated by the rapid increase in internet searches on the topic in Finland. At the same time, the weekly incidence of diagnoses of non-specific URTIs doubled. Paradoxically, the rate of prescriptions of antibiotics for URTIs started to decrease at the same time as the incidence of URTI diagnoses started to increase, to less than half of the estimate of the expected rate. In the previous years, the rate of antibiotics prescriptions has closely followed the incidence URTI diagnoses. These changes exceeded the 95\% CIs of the estimated expected values that account for the seasonality. The rate of prescriptions of antibiotics typically used for urinary tract infections remained stable at the same period. Moreover, the incidence of confirmed COVID-19 cases remained low even at the peak of the 
Table 3 The clinical characteristics of the groups for the periods 1 January 2017-31 December 2019 and 1 January 2020-21 June 2020

Measure

Unique persons

Total visits

Median age (10th, 90th percentiles)*

Gender, men

Gender, women

Acute upper respiratory tract infection URTI (J06; N, \% of total patients)

Influenza (J10; N, \% of total patients)

COVID-19 Tests (N, \% of total patients)

Confirmed COVID-19 infection (N, \% of suspected COVID-19 cases)

Urinary tract infection UTI (N, \% of total patients)

Prescription of antibiotics ( $N, \%$ of total patients)

\section{Period}

1 January 2017-31

December 2019

1 January 2020-21 June 2020

747241

187769

2910519403906

$41(14,64)$

$40(19,62)$

341798 (45.7\%)

80240 (42.7\%)

$405442(54.3 \%)$

$107528(57.3 \%)$

425202 (56.9)

92148 (49.1)

$4353(0.6) \quad 741(0.4)$

$0(0)$

21523 (11.5)

$0(0)$

$540(2.5)$

$15902(2.1)$

2801 (1.5)

$558823(74.8)$

The most notable differences in the periods are the inclusion of COVID-19 patients for the latter period, whose testing began in May 2020, and the smaller proportion of prescriptions for antibiotics for the latter period compared with the earlier.

${ }^{*}$ Calculated from total visits at the time of the event.

URTI, upper respiratory tract infection.

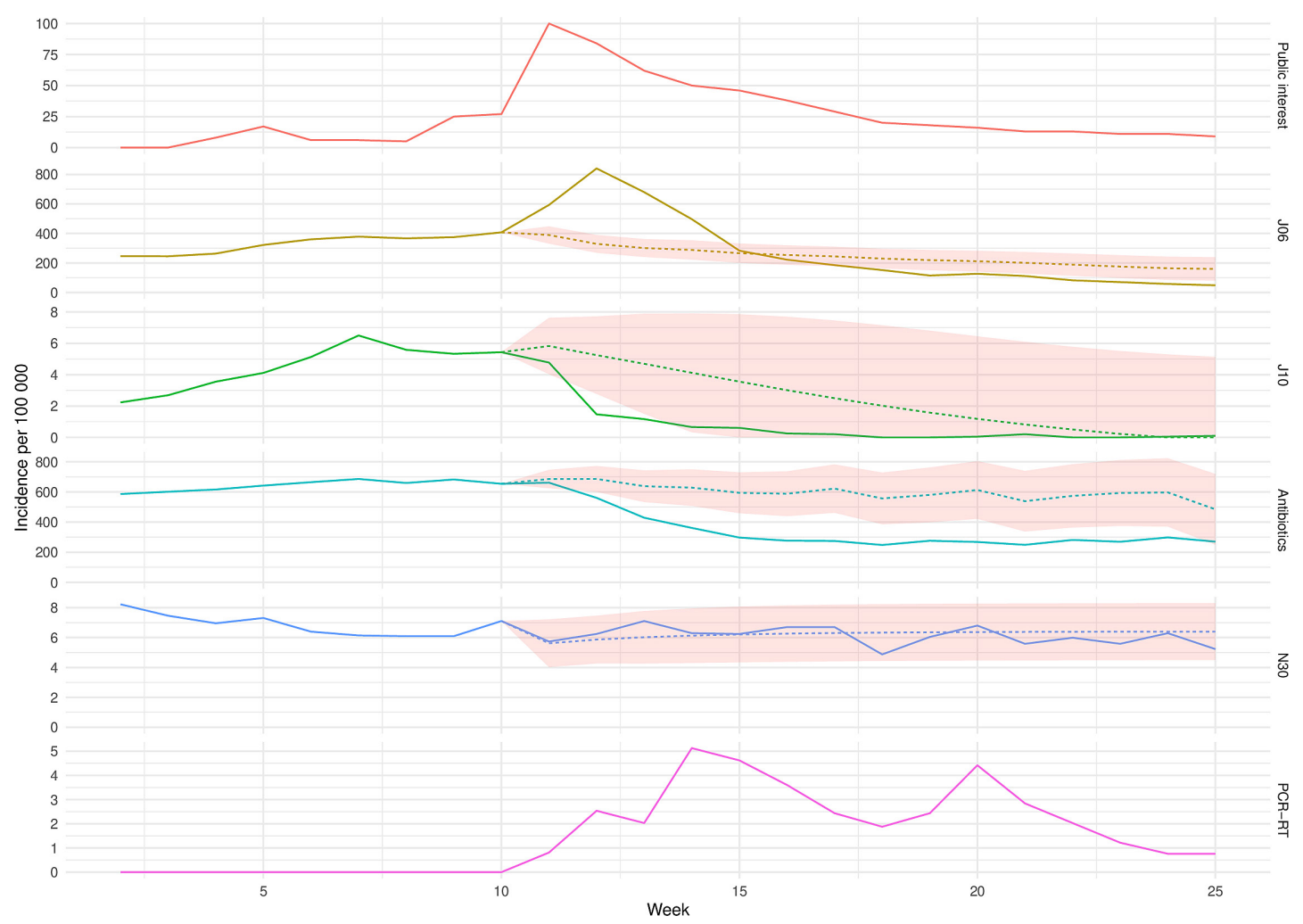

Figure 2 Public interest in COVID-19 and weekly incidence rates of upper respiratory tract infections, (J06), influenza (J10), prescriptions of antibiotics, urinary tract infections (N30), and confirmed COVID-19 infections for the year 2020. The measures are reported as incidence per 100000 inhabitants, except for the public interest, which is a relative measure from 0 to 100 , where 100 denotes the peak interest over the time period. The dashed line denotes the expected value estimates derived from the ARIMA model for the measures from week 11, with the $95 \% \mathrm{CI}$ shown as a red ribbon. ARIMA, autoregressive integrated moving average. 


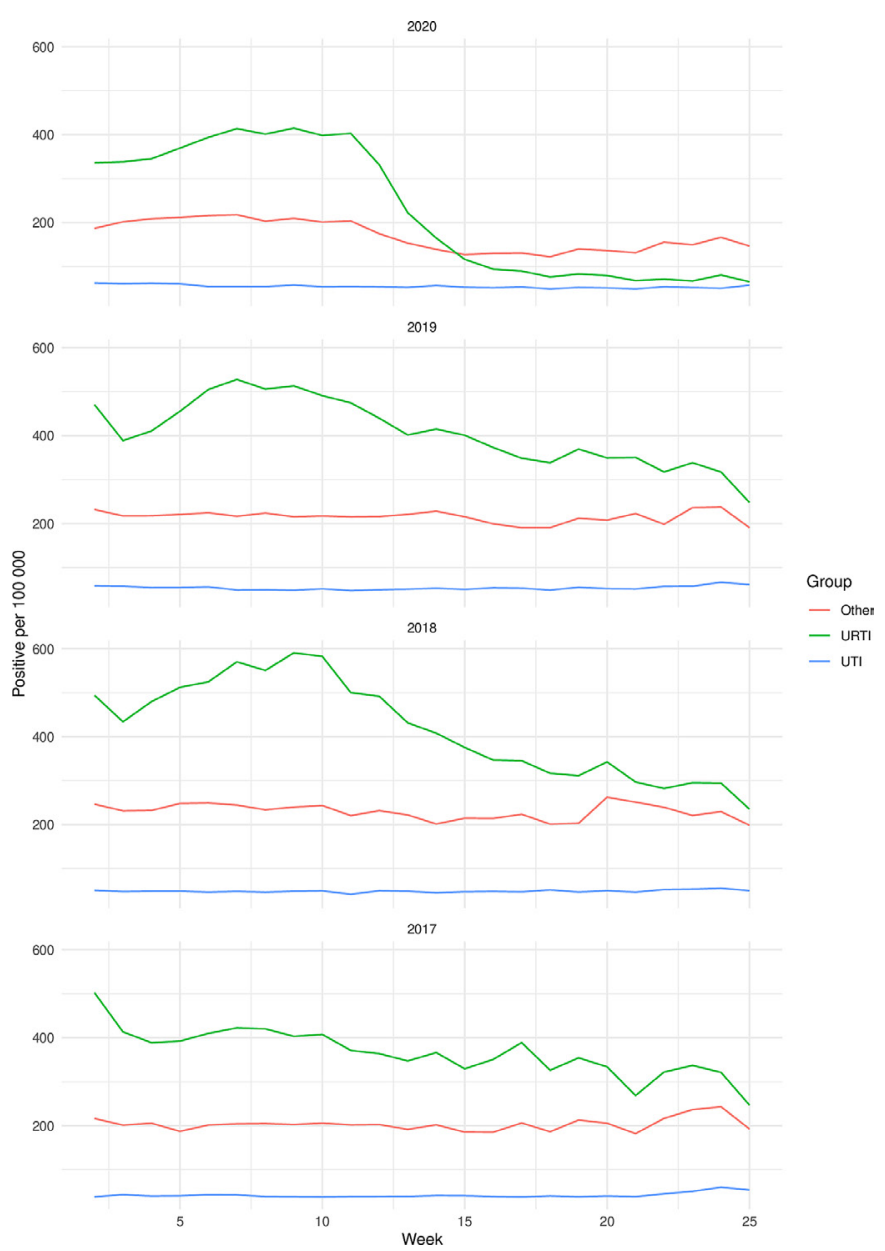

Figure 3 Yearly and weekly prescriptions of antibiotics per 100000 patients. The most notable change can be seen in 2020, with upper respiratory tract infection (URTI)related antibiotic prescriptions dropping sharply during the COVID-19 pandemic. A small change can be seen in other antibiotics, while no change can be seen in UTI-related antibiotics. The antibiotics are classified into respiratory system related antibiotics, urinary tract-related antibiotics and other antibiotics (table 2). UTI, urinary tract infection.

epidemic during spring 2020. We interpret these key findings as follows. First, simultaneously with the high level of media attention, many people were seeking medical advice with lower level of respiratory symptoms than usually. This, combined with the awareness of an epidemic of viral origin might have had an effect patients' demands for and physicians' patterns of prescribing antibiotics for URTIs.

\section{Comparison with other studies}

We are aware of only few other studies that has assessed healthcare utilisation rates during the COVID-19 pandemic. The number of visits to physicians decreased during the lockdown caused by the COVID-19 pandemic in a paediatric population in France. ${ }^{18}$ In the UK, all daily emergency department attendances decreased during the 2020 'COVID-19' period (12 March 2020 to 26 April 2020) and the reduction was greatest in less severe and non-respiratory indications, although a reduction in respiratory infections was also seen. ${ }^{19}$ Also, there is evidence of significant reductions of stroke and TIA admissions and gynaecological emergency department visits during the lockdowns. ${ }^{20-22}$ We noted a decreasing number of overall visits after the peak of the COVID-19 epidemic in line with the previous studies, but the rapid increase of patient contacts due to respiratory symptoms in our study differs from the previous findings.

\section{Strength and limitations of this study}

The prospectively collected and homogeneous registry data, comprising a large proportion of the Finnish population can be considered as a strength of our study. As always, registry data may contain errors, which may simultaneously be considered as a limitation. However, any systematic bias that would have occurred during the COVID-19 epidemic is unlikely and time trends in our data can be considered trustworthy. However, due to being a population-based cohort study the study is retrospective in nature, which may cause some bias. As Terveystalo is a private and occupational healthcare provider, the study population may more likely be employed, working age or have higher education than the general population. Our results of the COVID-19 incidence also match with the time trends of the national data. Moreover, we had access to a large set of data from the previous years, using which we were able to estimate the expected numbers for the selected outcomes with reasonable accuracy using the ARIMA model. Finally, our study focuses on temporal trends in the data, and does not imply causality between the simultaneous phenomena as such.

\section{Perspective}

The reasons for the variation of the selected diagnoses during the COVID-19 epidemic warrant further discussion. The relatively short period of increase in URTI diagnoses was followed by a decline to a lower level than the estimated expected rate, well below the rate before the COVID-19 epidemic (figure 2). The widespread lockdown, social distancing, and hygiene measures that took place shortly after the outbreak of the epidemic most likely have had an effect on the overall incidence of all infections that spread through contact and droplet routes, including URTIs and influenza. Also, before the COVID-19 testing capacity was sufficient, patients with COVID-19-like symptoms were typically advised to stay at home and remain in quarantine-like conditions voluntarily, a message emphasised in the news media also. Thus, it seems that people have largely stayed at home and have been hesitant to seek medical attention in the fear of COVID-19 infection from the care premises unless necessary, which may have resulted in underdiagnosis of the disease. It is also possible that some cases of COVID-19 were diagnosed as URTIs due to the limited testing capacity. Overall, in the early days of the COVID-19 pandemic we observed a sharp increase in the number of URTI diagnoses simultaneously with a wide media and public attention in Finland. Patients 
may have been seeking medical help with milder symptoms than usually. Shortly thereafter the phenomenon was reversed. Perhaps the increasing general awareness about COVID-19 reduced the eagerness of the patients to seek medical consultation with mild symptoms. Increased hygiene and restrictive measures may have influenced the underlying incidence of URTIs. These two combined may have resulted in a sharp decrease in the observed incidence of URTI diagnoses.

There are several issues possibly affecting both URTIs and influenza. First, patient behaviour seems to have varied during the observation period due to the increasing awareness. In addition, we cannot rule out potential socioeconomic factors affecting, for example, self-paying customers reducing healthcare utilisation due to economic uncertainty. Second, physician behaviour may have been influenced by the pandemic, and some cases of URTIs may have been misdiagnosed as COVID-19 or vice versa during the early stages of the pandemic. Primary care services capacity of Terveystalo was not relevantly restrained due to COVID-19, but laboratory testing capacity of COVID-19 was limited in the early stages of the pandemic. Additionally, the testing procedures and recommendations changed several times during the observation period, affecting both the observed positive test result rates and coinciding URTI diagnoses. Third, the variations in incidence can be due to a change in the underlying communicable disease epidemiology due to social distancing, restrictive measures and stricter hygiene measures, since no such variation was noted in the incidence of urinary tract diseases.

Our results also indicate a change in the physicians' practices at large during and after the peak of the COVID-19 epidemic. Due to the awareness of the new viral disease, patients with sufficiently severe respiratory symptoms were assigned to COVID-19 tests when indicated and advised to stay in isolation at home, unless there was a need for hospitalisation. This may also partly explain the rapid decline in the confirmed influenza diagnoses at the peak of URTI diagnoses (figure 2), which practically ended the influenza season 3-10 weeks earlier than predicted. Secondary bacterial infections may occur resulting in sinusitis, ear infection and rarely pneumonia after a viral respiratory infection. In Finland, the prescription of antibiotics for respiratory symptoms is typically limited to suspected or confirmed bacterial secondary infections. The reduction of the rate of prescriptions of antibiotics for URTIs that also remained at low level after the peak of the COVID-19 epidemic signals that in most cases the symptoms of the patients have been and remained relatively mild. In the aftermath of the epidemic, we have learnt that a low proportion of COVID-19 patients have a bacterial coinfection-less than in previous influenza pandemics. ${ }^{23}$ Of note, the reduction in the rate of prescriptions of antibiotics took place at the time when very little was known about the epidemic already, that is, it reflects the results of clinical judgement on symptoms by the physicians. Our findings are in line with the earlier ones that do not support the routine use of antibiotics in the management of confirmed COVID-19 infections. ${ }^{23}$

\section{CONCLUSIONS}

Our data show unforeseen trends in both patient and physician behaviours, especially during the peak of the COVID-19 epidemic, underlining the importance of preparedness of healthcare services to a pandemic. The demand of the type and volume of primary care services varied greatly during the epidemic simultaneously with the vast news and social media coverage of the topic. In times like these, the availability of easy-to-access primary care services and accurate online health information channels are important. If these kinds of services are not available, access to diagnostics and care of a significant proportion of COVID-19 patients might be overshadowed by a substantial number of worried patients with mild respiratory symptoms only. If COVID-19 infections are not timely diagnosed, properly treated and potential contacts tracked and quarantined, the disease is likely to spread further.

\section{Author affiliations}

${ }^{1}$ Terveystalo Healthcare, Helsinki, Finland

${ }^{2}$ Institute for Molecular Medicine Finland (FIMM), University of Helsinki, Helsinki, Finland

${ }^{3}$ Orthopedics and Traumatology, University of Helsinki and Helsinki University Hospital, Helsinki, Finland

${ }^{4}$ Faculty of Medicine, University of Helsinki, Helsinki, Finland

${ }^{5}$ Medical Microbiology and Immunoloy, University of Turku, Turku, Finland

\section{Twitter Sari Riihijärvi @SariRiihijarvi}

Contributors ON obtained the data for the study. ON, SR and ST designed the study. ON performed the statistical analysis and visualisations. ON, SR and ST drafted the manuscript. ON, AT, ST, PB, PH and SR participated actively in interpretation and discussion of the results, critical revision of the manuscript and approval of the final version. ON, AT and SR had full access to all the data in the study and take responsibility for the integrity of the data and the accuracy of the data analysis. SR is the guarantor. The corresponding author attests that all listed authors meet authorship criteria and that no others meeting the criteria have been omitted.

Funding The authors received funding from Terveystalo.

Competing interests ON, AT, ST, PB and SR were employed by Terveystalo during the conduct of the study. PB reports personal fees outside the submitted work during the last 36 months from Faron Pharmaceuticals, Oncorena and TILT Biotherapeutics. ST reports personal fees from DBC group of companies and grants from the Academy of Finland, Social Security Institution of Finland, and University of Helsinki, Finland, all outside the submitted work during the last 36 months. ON, PB and SR own Terveystalo stocks. Additional Stock ownerships: PB: TILT Biotherapeutics. An immediate family member of PB has Stock ownership Faron Pharmaceuticals. ST has stock ownership in DBC group of companies.

Patient consent for publication Not applicable.

Provenance and peer review Not commissioned; externally peer reviewed.

Data availability statement Data are available in a public, open access repository. Parts of the data are available in a public, open access repository: https:// avoinraportointi.terveystalo.com/korona/.

Supplemental material This content has been supplied by the author(s). It has not been vetted by BMJ Publishing Group Limited (BMJ) and may not have been peer-reviewed. Any opinions or recommendations discussed are solely those of the author(s) and are not endorsed by BMJ. BMJ disclaims all liability and responsibility arising from any reliance placed on the content. Where the content includes any translated material, BMJ does not warrant the accuracy and reliability 
of the translations (including but not limited to local regulations, clinical guidelines, terminology, drug names and drug dosages), and is not responsible for any error and/or omissions arising from translation and adaptation or otherwise.

Open access This is an open access article distributed in accordance with the Creative Commons Attribution Non Commercial (CC BY-NC 4.0) license, which permits others to distribute, remix, adapt, build upon this work non-commercially, and license their derivative works on different terms, provided the original work is properly cited, appropriate credit is given, any changes made indicated, and the use is non-commercial. See: http://creativecommons.org/licenses/by-nc/4.0/.

\section{ORCID iDs}

Oskar Niemenoja http://orcid.org/0000-0003-1809-0051

Simo Taimela http://orcid.org/0000-0001-6755-2983

Sari Riihijärvi http://orcid.org/0000-0001-8547-0252

\section{REFERENCES}

1 Coronavirus disease, 2019. Available: https://www.who.int/ emergencies/diseases/novel-coronavirus-2019/ [Accessed 1 Jul 2020].

2 Guan W-jie, Ni Z-yi, Hu Y, et al. Clinical characteristics of coronavirus disease 2019 in China. N Engl J Med Overseas Ed 2020;382:1708-20.

3 Arroll B. Common cold. BMJ Clin Evid 2011;2011:1510.

4 Wenzel RP, Fowler AA. Acute bronchitis. N Engl J Med Overseas Ed 2006;355:2125-30.

5 Terveyden ja hyvinvoinnin laitos. Tilannekatsaus koronaviruksesta - Infektiotaudit ja rokotukset - THL. thl.fi, 2020. Available: https:// thl.fi/fi/web/infektiotaudit-ja-rokotukset/ajankohtaista/ajankohtaistakoronaviruksesta-covid-19/tilannekatsaus-koronaviruksesta [Accessed 1 Jul 2020].

6 Petri M. Terveydenhuollon menot JA rahoitus, 2018.

7 Terveystalo 2019 annual review. Available: https://www.terveystalo. com/Global/Vuosikertomus 2019/Terveystalo_Annual_Review_2019. pdf [Accessed 2 Jul 2020].

8 Terveyden ja hyvinvoinnin laitos. Tautiluokitus ICD-10. Klassifikation AV sjukdomar. Luokitukset, termistöt JA tilasto-ohjeet, 2011.
9 Duodecim TFMS. Current care guidelines. Working group set up by the Finnish medical Society Duodecim and the Finnish medical societies. Available: https://www.kaypahoito.fi/ [Accessed $15 \mathrm{Apr}$ 2021].

10 Duodecim TFMS. Mikrobilääkesuositus: article in Lääkärin käsikirja (2021). Lääkärin käsikirja. Available: www.terveysportti.fi [Accessed 15 Apr 2021].

11 WHO. The anatomical therapeutic chemical classification system with defined daily doses (ATC/DDD). WHO, 2009.

12 Google trends. Available: https://trends.google.com/trends/?geo=US [Accessed 17 Jul 2020].

13 Bartholomew DJ, Jenkins GM. Time series analysis forecasting and control. J Oper Res Soc 1971;22:199-201.

14 Luo L, Luo L, Zhang X, et al. Hospital daily outpatient visits forecasting using a combinatorial model based on ARIMA and Ses models. BMC Health Serv Res 2017;17:469.

15 Ljung GM, BOX GEP. On a measure of lack of fit in time series models. Biometrika 1978;65:297-303.

$16 \mathrm{R}$ Core Team. R: a language and environment for statistical computing, 2019. Available: https://www.r-project.org/

17 Näin Suomi voi - Koronaepidemia - Terveystalo. Available: https:// avoinraportointi.terveystalo.com/korona/ [Accessed 1 Jul 2020]

18 Angoulvant F, Ouldali N, Yang DD, et al. Coronavirus disease 2019 pandemic: impact caused by school closure and national Lockdown on pediatric visits and admissions for viral and nonviral Infections - a time series analysis. Clin Infect Dis 2021;72:319-22.

19 Hughes HE, Hughes TC, Morbey R, et al. Emergency department use during COVID-19 as described by syndromic surveillance. Emerg Med J 2020;37:600-4.

20 Kristoffersen ES, Jahr SH, Thommessen B, et al. Effect of COVID-19 pandemic on stroke admission rates in a Norwegian population. Acta Neurol Scand 2020;142:632-6.

21 Frisullo G, Brunetti V, Di lorio R, et al. Effect of lockdown on the management of ischemic stroke: an Italian experience from a COVID Hospital. Neurol Sci 2020;41:2309-13.

22 Grandi G, Del Savio MC, Caroli M, et al. The impact of COVID-19 lockdown on admission to gynecological emergency departments: results from a multicenter Italian study. Int $J$ Gynecol Obstet 2020;151:39-42.

23 Lansbury L, Lim B, Baskaran V, et al. Co-Infections in people with COVID-19: a systematic review and meta-analysis. J Infect 2020;81:266-75. 